\title{
Three to tango: MUC1 as a ligand for both E-selectin and ICAM-1 in the breast cancer metastatic cascade
}

\author{
Yue Geng ${ }^{\dagger}$, Kimberly Yeh ${ }^{\dagger}$, Tait Takatani and Michael R. King *
}

Department of Biomedical Engineering, Cornell University, Ithaca, NY, USA

Edited by:

James L. Gulley, National Cancer

Institute, USA

\section{Reviewed by:}

Min Hee Kang, School of Medicine

Texas Tech University Health Sciences Center, USA

Jacalyn Rosenblatt, Harvard Medical School, USA

\section{${ }^{*}$ Correspondence:}

Michael R. King, Department of Biomedical Engineering, Cornell University, 205 Weill Hall, NY 14853, USA.

e-mail: mike.king@cornell.edu

${ }^{\dagger}$ Yue Geng and Kimberly Yeh have contributed equally to this work.
Cancer cell tethering and rolling on the vascular wall is facilitated by various selectin: glycoprotein interactions which lead to eventual extravasation and metastases. The aberrantly underglycosylated mucin MUC1 has been shown to both abundantly express selectin binding moieties (sialyl Lewis $x$ and a) and to consistently expose its core epitope. Flow cytometry was used to determine MUC1 expression on ZR-75-1 and MCF7 cells, while immunofluorescence microscopy was used to confirm the aberrant form of MUC1 and MUC1:ICAM-1 interactions. Each cell line was then perfused through combined E-selectin and ICAM-1 coated microtubes, as a model of the microvascular endothelium. ZR-75-1 and MCF7 were found to express abundant and low levels of underglycosylated MUC1, respectively. The rolling/adhesion profiles showed that ZR-75-1 cells, when compared to MCF7 cells, interact with E-selectin more efficiently resulting in sufficiently slow rolling velocities to form MUC1:ICAM-1 interactions thereby facilitating firm adhesion. The purpose and novelty of this work is the demonstration of the synergistic adhesion capabilities of MUC1 in the metastatic adhesion cascade, where the observed differential adhesion is consistent with the relative metastatic potential of the ZR-75-1 (highly metastatic) and MCF7 (weakly metastatic) cell lines.

Keywords: adhesion, breast cancer, circulation, E-selectin, ICAM-1, MUC1

\section{INTRODUCTION}

The mucin family of glycoproteins is traditionally associated with the protection of the epithelial layer and provides lubrication of luminal epithelial surfaces. More recently, certain mucins have been identified as markers for metastatic cancers. Of particular importance, the mucin MUC1 is overexpressed in numerous cancers including breast, ovarian, lung, pancreatic, prostate, gastric, and colorectal (Zotter et al., 1987; Girling et al., 1989; Ajioka et al., 1996; Burdick et al., 1997; Retz et al., 1998), where high expression generally correlates with increased mortality rates (MacLean et al., 1997; Guddo et al., 1998; Kocer et al., 2004; Duncan et al., 2007; Tewes et al., 2009). It is then reasonable to hypothesize that cancer's adaptation and alteration of MUC1 may play a vital role in metastatic progression.

Cancer metastasis through the bloodstream is initiated by the invasion of tumor cells from the primary site into the blood vessel (Moss and Anderson, 2000). These circulating tumor cells (CTCs) can then adhere to the endothelial lining, which leads to extravasation and the formation of secondary tumor sites. For CTC adhesion, cells may first establish transient interactions with the activated endothelium which facilitates cell tethering and rolling events (Tremblay et al., 2008; St Hill, 2011; Wirtz et al., 2011). These types of interactions are produced via selectins, a family of adhesion molecules expressed by the endothelium, and carbohydrate moieties, such as sialyl Lewis $\mathrm{x}\left(\mathrm{sLe}^{\mathrm{x}}\right)$ or sialyl Lewis a $\left(\mathrm{sLe}^{\mathrm{a}}\right)$, present on the selectin ligands expressed by CTCs (Borsig et al., 2002; Varki and Varki, 2007). Once the cell has sufficiently reduced its rolling velocity, firm adhesion can be acquired through the interaction between the intracellular cell adhesion molecule 1 (ICAM-1) on the endothelium and integrins on CTCs. This series of events is commonly referred to as the metastatic adhesion cascade (Orr et al., 2000).

MUC1 is not only overexpressed in many cancer types but is also aberrantly underglycosylated. The core structure of the extracellular domain of MUC1 mainly consists of 25-150 repeat units of 20 identical amino acid sequences rich in serines and threonines resulting in a length 5-10 times that of most membrane proteins. Normally, these amino acids would be richly O-glycosylated however aberrant MUC1 has been shown to express shortened oligosaccharides such as $\mathrm{sLe}^{\mathrm{x}}$ and $\mathrm{sLe} \mathrm{e}^{\mathrm{a}}$, and binds efficiently to E-selectin (Lloyd et al., 1996). Interestingly, high levels of MUC1 carrying sLe $\mathrm{s}^{\mathrm{x} / \mathrm{a}}$ correlate to poor prognosis in patients with lung adenocarcinoma (Inata et al., 2007). Aberrant MUC1 also has the propensity to expose its core epitope due to underglycosylation where it has become the target of various probes to determine MUC1 expression (Moore et al., 2004). Furthermore, ICAM-1 has been shown to recognize and bind to the core epitope of MUC1 (Hayashi et al., 2001). Therefore, CTCs may utilize aberrant MUC1 to facilitate tethering and rolling due to the increased length of MUC1 relative to other selectin ligands, and firmly adhere to the endothelium via ICAM-1 interactions (Regimbald et al., 1996).

In this study, we investigate the role of MUC1 in breast cancer cell adhesion under flow with two cell lines: ZR-75-1 which is known to have a high metastatic potential, and MCF7 which is weakly metastatic. The differential adhesion of these two cell lines 
to the endothelium are studied in vitro via micro-renathane tubes coated with varying ratios of E-selectin and ICAM-1 which represent a model of metastasis-prone microvasculature (Finzel et al., 2004). We hypothesize that the underglycosylated form of MUC1 may serve as a ligand for both E-selectin and ICAM-1, which would allow for efficient interaction between CTCs in transit and the inflamed endothelium.

\section{MATERIALS AND METHODS \\ REAGENTS}

Recombinant E-selectin-IgG 1 chimera and recombinant ICAM$1-\mathrm{IgG}_{1}$ chimera were purchased from R\&D systems (Minneapolis, MN, USA). Blotting grade blocker non-fat dry milk was obtained from Bio-Rad Laboratories (Hercules, CA, USA) and Protein-G was purchased from EMD Biosciences (San Diego, CA, USA). FITC mouse anti-human CD227 (clone HMPV), FITC mouse IgG1 $\mathrm{k}$ isotype control, purified mouse anti-human CD15s (clone CSLEX), APC rat anti-mouse IgM, and FITC goat anti-mouse $\operatorname{IgG} / \operatorname{IgM}$ were all purchased from BD Biosciences (San Jose, CA, USA). FITC mouse anti-human CD44v4 was obtained from AbD Serote (Germany). FITC and APC antihuman IgG antibodies were purchased from Invitrogen (Carmarillo, CA, USA). $\mathrm{Ca}^{2+}$ and $\mathrm{Mg}^{2+}$ free DPBS (Invitrogen, Camarillo, CA, USA), calcium carbonate (Sigma Chemical Co., St. Louis, MO, USA), low endotoxin ( $1 \mathrm{ng} / \mathrm{mg}$ ), and essentially globulinfree Bovine Serum Albumin (Sigma Chemical Co., St. Louis, MO, USA) were used to prepare flow buffer for cell adhesion assays.

\section{BREAST CANCER CELL CULTURE}

Breast cancer cell lines ZR-75-1 and MCF7 were purchased from ATCC and maintained in 10\% Fetal Bovine Serum (FBS; Cellgro), $1 \%$ penicillin-streptomycin (Invitrogen), and RPMI 1640 medium (ZR-75-1) or eagle's minimal essential medium with $0.01 \mathrm{mg} / \mathrm{mL}$ bovine insulin (MCF7) at $37^{\circ} \mathrm{C}$ with $5 \% \mathrm{CO}_{2}$ in a humidified incubator.
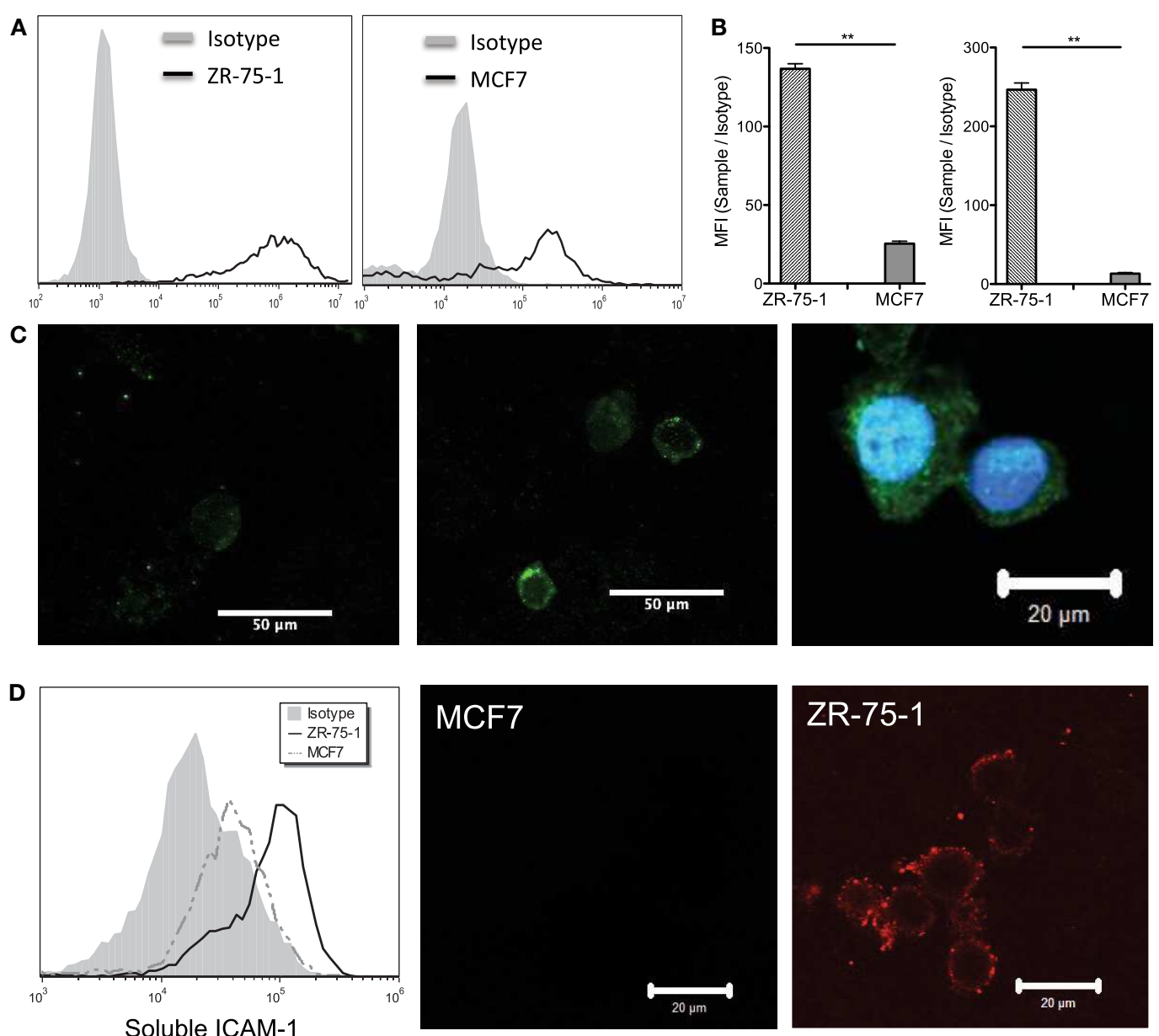

FIGURE 1 | (A) Flow cytometry histogram plots of ZR-75-1 and MCF7 labeled with anti-MUC1 mAb clone HMPV, respectively. (B) Quantification of the MFI ratio of sample/isotype for both cell types with anti-MUC1 mAb clone SM3 and HMPV, respectively. Student's $t$-test was used for statistical analysis and results from both labeling experiments were found to be significantly different for ZR-75-1 and MCF7 cells ( $p \leq 0.01)$. (C) Left and middle: confocal microscopy images of MCF7 and ZR-75-1 labeled with anti-MUC1 mAb (clone SM3), respectively. Right: strong signal of SM3 anti-MUC1 mAb in the cytoplasmic region of select ZR-75-1 cells. (D) Left: flow cytometry histogram of fluorescently tagged ICAM-1 labeling on ZR-75-1 and MCF7 cells. Middle and right: confocal microscopy images of MCF7 and ZR-75-1 cells labeled with fluorescently tagged ICAM-1. 


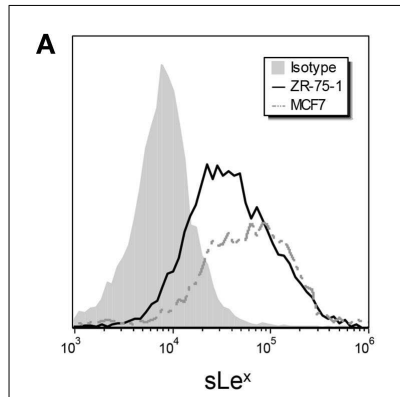

B
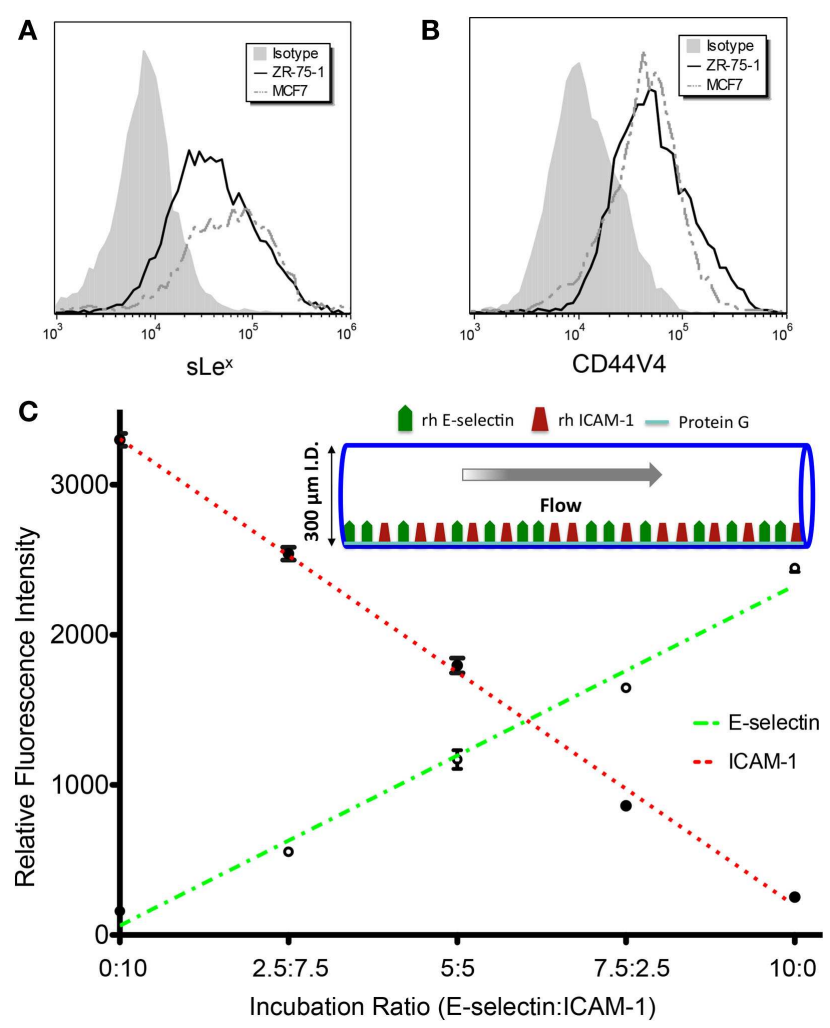

FIGURE 2 | (A,B) Flow cytometry histogram overlays of ZR-75-1 and MCF7 cells labeled with anti-sLe (clone CSLEX) mAb and anti-CD44V4 mAb, respectively. (C) E-selectin and ICAM-1 fluorescence intensities as concentration ratios vary during surface preparation. The $r^{2}$ values for E-selectin and ICAM-1 fluorescence intensity trend lines were found to be 0.986 and 0.995 , respectively.

\section{FLOW CYTOMETRY}

Cells were removed from tissue culture flasks prior to antibody incubation using an enzyme-free cell dissociation buffer solution. After washing with $1 \times$ DPBS, the cells were resuspended in $1 \%$ BSA in DPBS to a final concentration of approximately 250,000 cells in each sample. Antibodies against MUC1 or appropriate isotype controls were added to the cell suspensions and incubated over ice for $45 \mathrm{~min}$. Specifically, mouse anti-human MUC1 mAb clone HMPV (reacts with the core peptide of MUC1) and mouse anti-human MUC1 mAb clone SM3 (recognizes the underglycosylated form of MUC1) were used in this study. Following incubation, cells were washed twice with $500 \mu \mathrm{L}$ of $1 \%$ BSA to remove any unbound antibody. Flow cytometry samples were analyzed using a BD Accuri C6 flow cytometer (Ann Arbor, MI, USA).

\section{SOLUBLE ICAM-1 BINDING ASSAY}

Recombinant human ICAM-1-IgG 1 chimeric protein (R\&D) was fluorescently tagged with Alexa 647 anti-human IgG antibody and incubated with ZR-75-1 and MCF7 cells in 1× DPBS with 2\% BSA for $30 \mathrm{~min}$ at room temperature. Unbound proteins were washed off with $1 \times$ DPBS twice prior to flow cytometry and confocal microscopy imaging.

\section{PREPARATION OF COMBINED PROTEIN SURFACES}

Micro-renathane tubings (microtubes) with an inner diameter of $300 \mu \mathrm{m}$ (Braintree Scientific Inc., Braintree, MA, USA) were cut to lengths of $50 \mathrm{~cm}$. Recombinant human E-selectin- $\mathrm{IgG}_{1}$ and ICAM-1-IgG 1 chimeric proteins were each dissolved in $1 \times$ PBS and mixed in various ratios (E-sel/ICAM-1: 10/0, 7.5/2.5, 5/5, $2.5 / 7.5,0 / 10)$ to a final protein concentration of $10 \mu \mathrm{g} / \mathrm{mL}$. The microtube surface was first rinsed with $1 \times$ DPBS and then incubated with $10 \mu \mathrm{g} / \mathrm{mL}$ of protein-G solution for $1 \mathrm{~h}$, followed by a $2 \mathrm{~h}$ incubation with the premixed E-selectin and ICAM-1 protein solution, then blocked with 5\% milk protein in PBS for $1 \mathrm{~h}$. To evaluate the correlation between incubation concentrations and surface coverage, FITC conjugated E-selectin and APC conjugated ICAM-1 were mixed in the ratios described above. Fluorescence images were taken and analyzed using Image $\mathrm{J}^{1}$

\section{CELL ADHESION ASSAY}

After surface functionalization as described above, microtubes were secured to the stage of an Olympus IX81 motorized inverted microscope (Olympus America, Melville, NY, USA). A CCD camera (model no: KP-M1AN, Hitachi, Tokyo, Japan) and a DVD recorder (model no: DVD-1000MD, Sony Electronics) were used to record experiments for offline analysis. ZR-75-1 and MCF7 breast cancer cells suspended in flow buffer were perfused through protein coated microtubes using a syringe pump (KDS 230, IITC Life Science, Woodland Hills, CA, USA) at a wall shear stress of 1.0 dyne $/ \mathrm{cm}^{2}$.

\section{CONFOCAL IMMUNOFLUORESCENCE MICROSCOPY}

ZR-75-1 and MCF7 cells were removed from tissue culture flasks, washed with $1 \times$ DPBS, resuspended with $2 \%$ BSA in $1 \times$ DPBS, loaded to a pre-assembled cytospin cuvette, and spun at $750 \mathrm{rpm}$ for $3 \mathrm{~min}$ in a Shandon Cytospin 3 centrifuge (Harlow Scientific, Arlington, MA, USA). Cytospin slides were then dried and fixed with 4\% paraformaldehyde (Electron Microscopy Sciences, Hatfield, PA, USA) prior to antibody labeling. Indirect surface staining for MUC1 was performed using mouse anti-human MUC1 mAb (clone SM3) and Alexa 647 rat anti-mouse mAb as a secondary antibody. For some cytospin slides, nuclear staining with DAPI was performed for $10 \mathrm{~min}$ at room temperature prior to imaging. Samples from the soluble ICAM-1 binding assay were deposited on cytospin slides for imaging. A Zeiss 710 laser scanning confocal microscope at the Cornell University microscopy and imaging core facility was used to collect images using a $40 \times$ objective.

\section{DATA ACOUISITION AND ANALYSIS}

"Rolling" cells were defined as those observed to translate in the direction of flow with an average velocity less than $50 \%$ of the calculated hydrodynamic free stream velocity. The rolling velocity was calculated by measuring the distance a rolling cell traveled over a $30 \mathrm{~s}$ interval. Videos of rolling cells were taken at three randomly selected locations along the microtube. "Tethering" cells were defined as cells that were observed to roll intermittently with fluctuating velocity. The quantity of cells rolling, adherent and

\footnotetext{
${ }^{1}$ http://rsbweb.nih.gov/ij/
} 


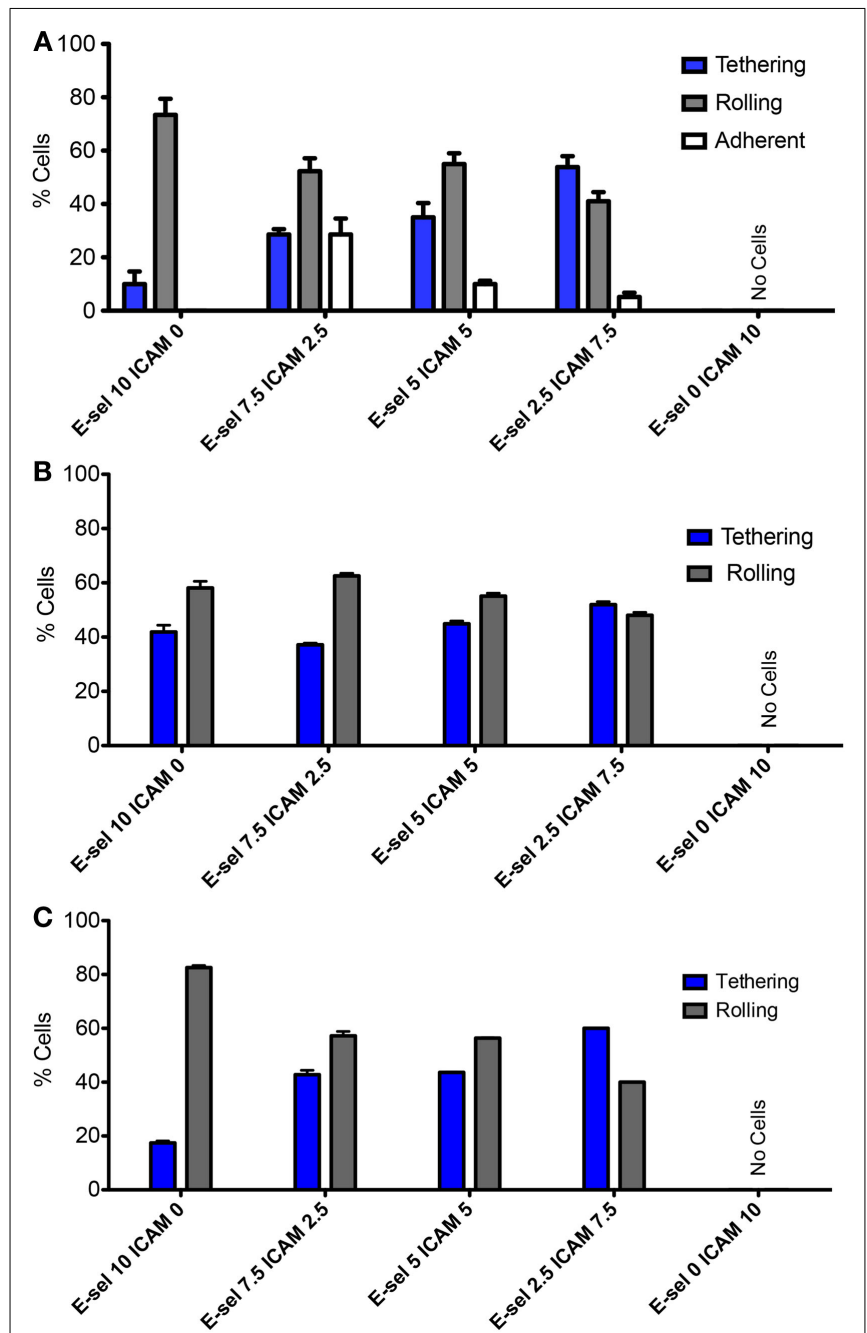

FIGURE 3 |Adhesion phenotypes on combined protein surface under physiological flow of (A) ZR-75-1, (B) MCF7, and (C) SM3 blocked

ZR-75-1 cells. Two-way ANOVA was used for statistical analysis and results from all conditions were found to be significantly different $(p \leq 0.001)$.

tethering was determined by recording images at 30 randomly selected locations along the microtube. All errors are reported as standard error of the mean, and statistical analyses were performed using Prism (GraphPad Software, San Diego, CA, USA).

\section{MOLECULAR DYNAMICS}

The crystal structure of SM3 bound to the MUC1 core fragment (1SM3; Dokurno et al., 1998) was obtained from the Protein Data Bank for use as starting coordinates. The MUC1 fragment was equally extended beyond the SM3:MUC1 interaction to include all amino acids of one complete tandem repeat unit (PATSGPAPRTDPASTVGHAP) and the furthest threonine/serine from SM3 was O-glycosylated with the $\mathrm{sLe}^{\mathrm{x}}$ carbohydrate group. Using the YASARA ${ }^{2}$ package of molecular dynamics (MD) programs, the complex was solvated in a water cube with an initial

${ }^{2}$ http://yasara.org
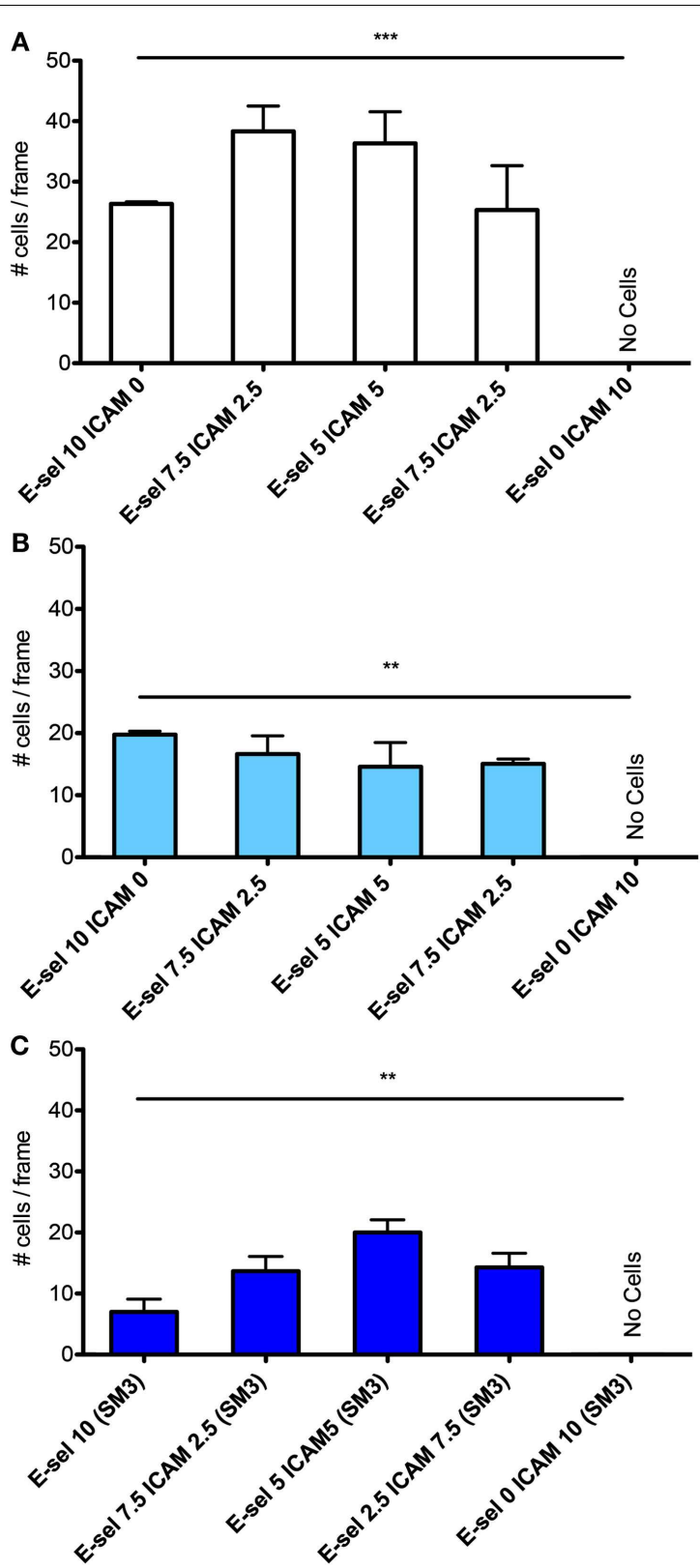

FIGURE 4 | Quantification of average number of cells captured on the surfaces with varying ratios of E-selectin and ICAM-1 for (A) ZR-75-1, (B) MCF7, and (C) SM3 blocked ZR-75-1 cells. One-way ANOVA was used for statistical analysis. For all three experiments, results from all conditions were found to be significantly different with $p$-values of $0.0008,0.0093$, and 0.0016 for ZR-75-1, MCF7, and SM3 blocked ZR-75-1, respectively. ${ }^{*} p \leq 0.01 ;{ }^{* *} p \leq 0.001$.

length of $100 \AA$ to allow for free protein rotation and neutralized to $0.9 \% \mathrm{NaCl}$ with physiologically neutral $\mathrm{pH}$ (7.4). The YAMBER3 self-parameterizing force field (Krieger et al., 2004) was implemented with periodic boundary conditions, the particle mesh Ewald method for electrostatic interactions (Essmann et al., 1995) and a recommended $7.86 \AA$ force cutoff for longrange interactions. Temperature and pressure were held constant 
at $300 \mathrm{~K}$ and $1 \mathrm{~atm}$, respectively, while the water box was allowed to adjust slightly to constrain the water density to $0.997 \mathrm{~g} / \mathrm{L}$. Conformational stresses were then removed via short steepest descent minimizations and simulated annealing was run until sufficient convergences were reached. A free dynamics simulation was then run for $10 \mathrm{~ns}$ to obtain the final equilibrated structure.

\section{RESULTS}

\section{DIFFERENTIAL MUC1 EXPRESSION ON ZR-75-1 AND MCF7 CELLS AND THEIR ABILITY TO BIND TO ICAM-1 UNDER STATIC CONDITIONS}

MUC1 core peptide expression was measured for both ZR-751 and MCF7 cells via flow cytometry using MUC1 mAb clone HMPV and found to be significantly higher on ZR-75-1 cells

(Figure 1A). MUC1 mAb clone SM3 was also used to detect the underglycosylated form of MUC1, which has been identified as a tumor associated form of MUC1 (Mommers et al., 1999). Although no significant shift was observed, mean fluorescence intensity (MFI) of sample/isotype for ZR-75-1 cells was observed to be five times higher than MCF7 cells (Figure 1B). Furthermore, confocal microscopy images with MUC1 antibody (SM3) labeling showed brighter signals on ZR-75-1 cells (Figure 1C). Strong homogenous cytoplasmic staining of MUC1 (SM3) was observed on some ZR-75-1 cells (Figure 1C right) but not on MCF7 cells. To assay MUC1:ICAM-1 binding under static conditions, human recombinant ICAM-1 was conjugated with a fluorescently tagged secondary antibody and incubated with both cell types. Flow cytometry and confocal microscopy results both showed significantly stronger binding of ICAM-1 to ZR-75-1 cells compared to MCF7 cells (Figure 1D).

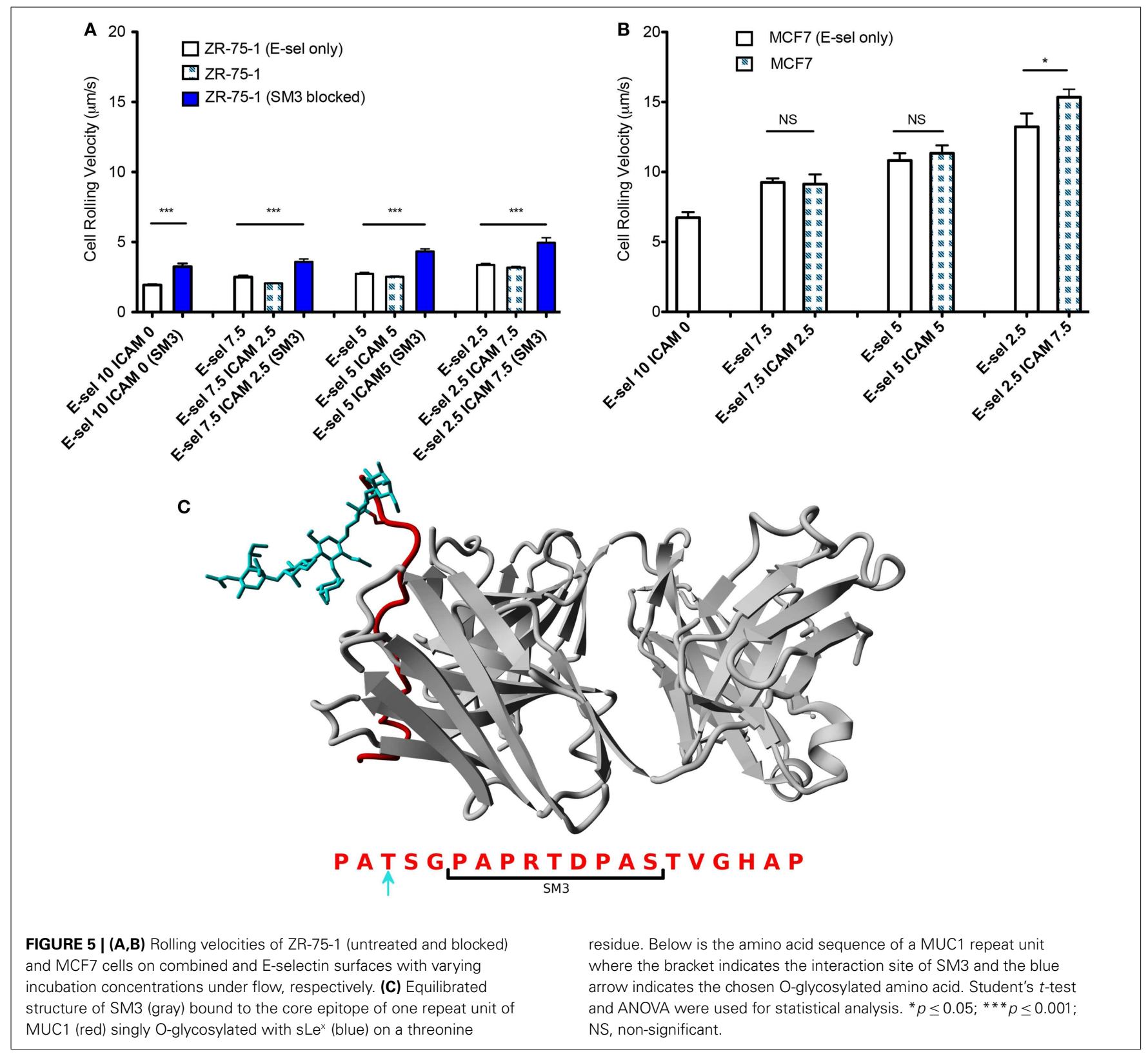




\section{E-SELECTIN LIGAND AND BINDING MOIETY EXPRESSION ON ZR-75-1 AND MCF7 CELLS}

The MFI ratios of sample over isotype control for the E-selectin binding moiety sLe ${ }^{\mathrm{x}}$ expression on ZR-75-1 and MCF7 were found to be 8.43 and 8.56, respectively, via flow cytometry (Figure 2A). CD44 variant 4 (CD44v4), among the multiple variants of common E-selectin ligand CD44, has been identified as a major Eselectin ligand for breast cancer cells (Zen et al., 2008). CD44v4 expression was measured on ZR-75-1 and MCF7 cells via flow cytometry and no significant difference was observed (Figure 2B).

\section{E-SELECTIN AND ICAM-1 COMBINED SURFACE}

The initial layer of protein-G orients the adhesion molecules to maximally interact with cell surfaces as the cells are perfused through the tubes. As the E-selectin:ICAM-1 concentration ratios were increased, the fluorescence intensity of bound E-selectin in the microtube was found to linearly increase while ICAM-1 fluorescence linearly decreased (Figure 2C), verifying the desired protein concentrations on the microtube surfaces.

\section{MUC1 IS INVOLVED IN THE CANCER ADHESION CASCADE IN ASSOCIATION WITH E-SELECTIN AND ITS LIGANDS}

Figures 3A,B divide the cells that interact with the surface into three categories: tethering, rolling, and adherent. ZR-75-1 cells were found to roll quite consistently when E-selectin was present at any concentration on the surface where there was a slight decrease in the percent of rolling cells as the E-selectin concentration decreases (Figure 3A). Conversely, the percent of ZR-75-1 tethering cells increased as the E-selectin:ICAM-1 ratio decreased.
Interestingly, adherent ZR-75-1 cells were observed only when both E-selectin and ICAM-1 exist on the surface and 7.5:2.5 was found to be the optimal ratio of E-selectin:ICAM-1 that yields the greatest number of adherent cells. However, as the Eselectin:ICAM-1 ratio decreased so did the percent of adherent cells. On the other hand, MCF7 rolling and tethering showed little sensitivity to varying the E-selectin:ICAM-1 ratios where MCF7 tethering cells only slightly increased as the ratio decreased, as shown in Figure 3B. Most notably, no adherent MCF7 cells were observed on the surface for any concentration ratio. For both ZR75-1 and MCF7 cells, when only ICAM-1 coats the surface no cells interacted adhesively under flow. Anti-MUC1 mAb (clone SM3) was found to block the adhesive interactions of ZR-75-1 cells with the surface, leaving only the tethering and rolling populations (Figure 3C).

The cell flux for each cell type (Figures 4A-C) shows little sensitivity to the combined surface concentration ratios. However, overall the ZR-75-1 cell flux is much greater than both MCF7 and SM3 blocked ZR-75-1 cell fluxes, roughly by a factor of 2. Comparing ZR-75-1 to MCF7 and SM3 blocked ZR-75-1 cells, the cell fluxes inversely correlate with the cell rolling velocities, as shown in Figures 5A,B, where the ZR-75-1 cell rolling velocities were found to be slower than MCF7 cell rolling velocities. For example, for surfaces coated with only E-selectin, MCF7 cells rolled at $6.74 \pm 0.40 \mu \mathrm{m} / \mathrm{s}$ whereas ZR-75-1 cells rolled at $1.93 \pm 0.06 \mu \mathrm{m} / \mathrm{s}$. SM3 blockade was found to cause an increase in rolling velocity to approximately $4 \mu \mathrm{m} / \mathrm{s}$, significantly faster than untreated cells. A structure of SM3 bound to the underglycosylated core epitope of MUC1 is depicted in Figure 5C, where SM3 not only blocks

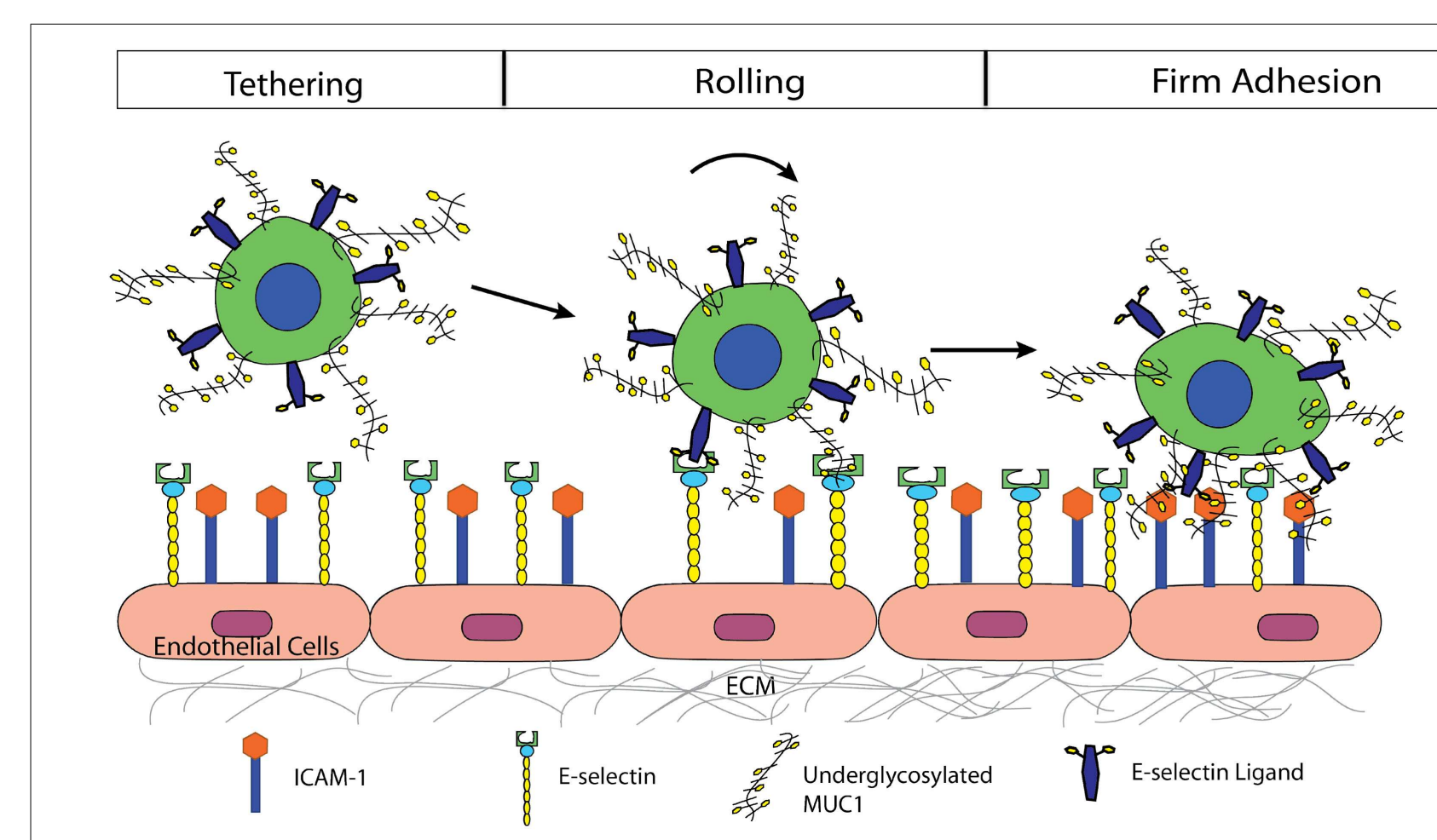

FIGURE 6 | Proposed mechanism by which MUC1 can act as a ligand for E-selectin, initiating tethering, and rolling events of CTCs on the endothelium, and subsequently serve as an ICAM-1 ligand, mediating firm adhesion of CTCs. 
ICAM-1 interactions, but is sufficiently bulky compared to sLe $\mathrm{x}^{\mathrm{x}}$ to inhibit some amount of E-selectin interactions as well. Unlike cell flux, both ZR-75-1 (untreated and blocked) and MCF7 cell rolling velocities were sensitive to the E-selectin concentration where cell rolling velocities increased as the E-selectin concentration decreased (Figures 5A,B). Furthermore, the MCF7 cell rolling velocity at the lowest E-selectin concentration was double that of the cell rolling velocity at the highest E-selectin concentration which shows a greater sensitivity to E-selectin compared to ZR-75-1 cells.

\section{DISCUSSION}

The detection and enumeration of CTCs holds great potential in breast, colorectal, and prostate cancer prognosis, yet the basic biophysics of how these CTCs interact with the endothelium is not fully understood. Similar to leukocyte recruitment to the endothelium, CTC tethering and rolling on the blood vessel wall under hydrodynamic shear stress are also mediated by the selectin family of adhesion molecules (Geng et al., 2012). After stable rolling on the endothelium, leukocytes can firmly adhere to the inflamed endothelium via leukocyte beta-2 integrin (Mac-1, LFA-1): ICAM-1 binding (Diamond et al., 1990; Ding et al., 1999; King, 2006). Similarly for epithelial-type CTCs, tumor associated MUC1 may play the role of beta-2 integrins on leukocytes by binding ICAM-1 to enable firm adhesion and initiate subsequent events in the metastatic cascade (Rahn et al., 2005).

Tumor associated MUC1 on breast cancer cells was first identified as a novel adhesion ligand for endothelial ICAM-1 by Regimbald et al. (1996) via static adhesion assays between MCF7 cells and stimulated HUVEC cells as well as immobilized recombinant ICAM-1. MCF7 cells do not express common ICAM-1 ligands, such as LFA-1, Mac-1, or CD43. However under static conditions, MUC1 was found to interact with ICAM-1, which could mediate firm adhesion of CTCs to the inflamed endothelium. In contrast, we characterized the adhesive role of tumor associated MUC1 under hydrodynamic shear stress by perfusing both ZR-75-1 (which overexpresses MUC1) and MCF7 cells through functionalized microtubes, more representative of the blood vessel microenvironment. Furthermore, the inflamed endothelium was simulated by immobilizing both E-selectin and ICAM-1 with varying ratios on the microtube surface, creating a more physiologically relevant and controllable environment to study the adhesion events of circulating ZR-75-1 and MCF7 cells under flow.

\section{REFERENCES}

Ajioka, Y., Allison, L. J., and Jass, J. R. (1996). Significance of MUC1 and MUC2 mucin expression in colorectal cancer. J. Clin. Pathol. 49, 560-564.

Borsig, L., Wong, R., Hynes, R. O., Varki, N. M., and Varki, A. (2002). Synergistic effects of L- and Pselectin in facilitating tumor metastasis can involve non-mucin ligands and implicate leukocytes as enhancers of metastasis. Proc. Natl. Acad. Sci. U.S.A. 99, 2193-2198.
Burdick, M. D., Harris, A., Reid, C. J., Iwamura, T., and Hollingsworth, M. A. (1997). Oligosaccharides expressed an MUC1 produced by pancreatic and colon tumor cell lines. J. Biol. Chem. 272, 24198-24202.

Diamond, M. S., Staunton, D. E., Defougerolles, A. R., Stacker, S. A., Garciaaguilar, J., Hibbs, M. L., and Springer, T. A. (1990). ICAM1 (CD54) - a counter-receptor for MAC-1 (CD11B CD18). J. Cell Biol. 111, 3129-3139.

ZR-75-1 cells show a much greater expression of underglycosylated MUC1 compared to MCF7 cells, which significantly affects their adhesion behavior when perfused through the combined surface microtubes. Interestingly, although ZR-75-1 and MCF7 cells have similar expression levels of $s \mathrm{Le}^{\mathrm{x}}$, one of the E-selectin binding moieties, ZR-75-1 cells roll on the combined protein surface at a significantly slower rolling velocity, indicating that ZR-75-1 cells establish stronger interactions with E-selectin. Recall that underglycosylated forms of MUC1 also contain shortened oligosaccharides where $\mathrm{sLe}^{\mathrm{x}}$ is one of the most common carbohydrates of aberrant MUC1 (Burdick et al., 1997). Therefore MUC1, when appropriately decorated with $\mathrm{sLe}^{\mathrm{x}}$ in its underglycosylated form, is expected to extend further from the cell surface compared to other selectin ligands due to its size and is perhaps more able to interact with E-selectin to efficiently mediate tethering and rolling events. The greater rolling velocities of ZR-75-1 cells blocked with SM3 also suggests MUC1 is an important E-selectin ligand because SM3 could inhibit some amount of E-selectin:MUC1 interactions due to the size of SM3 compared to $\mathrm{SLe}^{\mathrm{x}}$ (Figure 5C). As a result of the slower rolling velocity and greater MUC1 expression, only ZR-75-1 cells firmly adhered to the combined surface, where firm adhesion is facilitated by MUC1:ICAM-1 interactions. In our study, the observation of firmly adhered cells to the combined surface under shear stress is consistent with the metastatic potential of the ZR-75-1 cell line (highly metastatic) and the MCF7 cell line (weakly metastatic).

In conclusion, we propose a mechanism by which MUC1 can act as a ligand for E-selectin, initiating tethering and rolling events of CTCs on the endothelium, and subsequently serve as an ICAM1 ligand, mediating firm adhesion of CTCs (Figure 6). The synergistic effect of MUC1:E-selectin and MUC1:ICAM-1 may play an important role in breast cancer metastasis through the bloodstream where underglycosylated MUC1 can significantly slow the rolling velocity of CTCs thereby allowing for more frequent occurrence of firm adhesion events and subsequent extravasation. In summary, our results provide new insights into the roles of MUC1 in the metastatic adhesion cascade and suggests future examination into clinical aspects where the underglycosylated form of MUC1 can be targeted since aberrantly underglycosylated MUC1 expression is highly correlated to poor prognosis in breast and colon cancer patients.

\section{ACKNOWLEDGMENTS}

This work was funded by NIH Grant U54CA143876 to Michael R. King, and NSF Graduate Fellowship to Yue Geng.

Ding, Z. M., Babensee, J. E., Simon, S. I., Lu, H. F., Perrard, J. L., Bullard,

D. C., Dai, X. Y., Bromley, S. K., Dustin, M. L., Entman, M. L., Smith, C. W., and Ballantyne, C. M. (1999). Relative contribution of LFA-1 and Mac-1 to neutrophil adhesion and migration. J. Immunol. 163, 5029-5038.

Dokurno, P., Bates, P. A., Band, H. A., Stewart, L. M. D., Lally, J. M., Burchell, J. M., TaylorPapadimitriou, J., Snary, D., Sternberg, M. J., and Freemont,
P. S. (1998). Crystal structure at 1.95 angstrom resolution of the breast tumour-specific antibody SM3 complexed with its peptide epitope reveals novel hypervariable loop recognition. J. Mol. Biol. 284, 713-728.

Duncan, T. J., Watson, N. F. S., AlAttar, A. H., Scholefield, J. H., and Durrant, L. G. (2007). The role of MUC1 and MUC3 in the biology and prognosis of colorectal cancer. World J. Surg. Oncol. 5,31 . 
Essmann, U., Perera, L., Berkowitz, M. L., Darden, T., Lee, H., and Pedersen, L. G. (1995). A smooth particle mesh Ewald method. J. Chem. Phys. 103, 8577-8593.

Finzel, A., Reininger, A., Bode, P., and Wurzinger, L. (2004). ICAM-1 supports adhesion of human small-cell lung carcinoma to endothelial cells. Clin. Exp. Metastasis 21, 185-189.

Geng, Y., Marshall, J. R., and King, M. R. (2012). Glycomechanics of the metastatic cascade: tumor cellendothelial cell interactions in the circulation. Ann. Biomed. Eng. 40, 790-805.

Girling, A., Bartkova, J., Burchell, J., Gendler, S., Gillett, C., and TaylorPapadimitriou, J. (1989). A core protein epitope of the polymorphic epithelial mucin detected by the monoclonal-antibody SM-3 is selectively exposed in a range of primary carcinomas. Int. J. Cancer 43, 1072-1076.

Guddo, F., Giatromanolaki, A., Koukourakis, M. I., Reina, C., Vignola, A. M., Chlouverakis, G., Hilkens, J., Gatter, K. C., Harris, A. L., and Bonsignore, G. (1998). MUC1 (episialin) expression in non-small cell lung cancer is independent of EGFR and c-erbB-2 expression and correlates with poor survival in node positive patients. J. Clin. Pathol. 51, 667-671.

Hayashi, T., Takahashi, T., Motoya, S., Ishida, T., Itoh, F., Adachi, M., Hinoda, Y., and Imai, K. (2001). MUC1 mucin core protein binds to the domain 1 of ICAM-1. Digestion 63 (Suppl. 1), 87-92.

Inata, J., Hattori, N., Yokoyama, A., Ohshimo, S., Doi, M., Ishikawa, N., Hamada, H., and Kohno, N. (2007). Circulating KL-6/MUC1 mucin carrying sialyl Lewis(a) oligosaccharide is an independent prognostic factor in patients with lung adenocarcinoma. Int. J. Cancer 120, 2643-2649.

King, M. R. (2006). Principles of Cellular Engineering: Understanding the
Biomolecular Interface. Burlington: Academic Press.

Kocer, B., Soran, A., Kiyak, G., Erdogan, S., Eroglu, A., Bozkurt, B., Solak, C. and Cengiz, O. (2004). Prognostic significance of mucin expression in gastric carcinoma. Dig. Dis. Sci. 49, 954-964.

Krieger, E., Darden, T., Nabuurs, S. B., Finkelstein, A., and Vriend, G. (2004). Making optimal use of empirical energy functions: forcefield parameterization in crystal space. Proteins 57, 678-683.

Lloyd, K. O., Burchell, J., Kudryashov, V., Yin, B. W. T., and TaylorPapadimitriou, J. (1996). Comparison of O-linked carbohydrate chains in MUC-1 mucin from normal breast epithelial cell lines and breast carcinoma cell lines-demonstration of simpler and fewer glycan chains in tumor cells. J. Biol. Chem. 271, 33325-33334.

MacLean, G. D., Reddish, M. A., and Longenecker, B. M. (1997). Prognostic significance of preimmunotherapy serum CA27.29 (MUC-1) mucin level after active specific immunotherapy of metastatic adenocarcinoma patients. $J$. Immunother. 20, 70-78.

Mommers, E. C., Leonhart, A. M., von Mensdorff-Pouilly, S., Schol, D. J., Hilgers, J., Meijer, C. J., Baak, J. P., and van Diest, P. J. (1999). Aberrant expression of mucl mucin in ductal hyperplasia and ductal carcinoma in situ of the breast. Int. J. Cancer 84, 466-469.

Moore, A., Medarova, Z., Potthast, A., and Dai, G. (2004). In vivo targeting of underglycosylated MUC-1 tumor antigen using a multimodal imaging probe. Cancer Res. 64, 1821-1827.

Moss, M. A., and Anderson, K. W. (2000). Adhesion of cancer cells to endothelial monolayers: a study of initial attachment versus firm adhesion. J. Adhes. 74, 19-40.

Orr, F. W., Wang, H. H., Lafrenie, R. M., Scherbarth, S., and Nance,
D. M. (2000). Interactions between cancer cells and the endothelium in metastasis. J. Pathol. 190, 310-329.

Rahn, J., Chow, J., Horne, G., Mah, B., Emerman, J., Hoffman, P., and Hugh, J. C. (2005). MUC1 mediates transendothelial migration in vitro by ligating endothelial cell ICAM-1. Clin. Exp. Metastasis 22, 475-483.

Regimbald, L. H., Pilarski, L. M., Longenecker, B. M., Reddish, M. A., Zimmermann, G., and Hugh, J. C. (1996). The breast mucin MUC1 as a novel adhesion ligand for endothelial intercellular adhesion molecule 1 in breast cancer. Cancer Res. 56, 4244-4249.

Retz, M., Lehmann, J., Roder, C., Plotz, B., Harder, J., Eggers, J., Pauluschke, J., Kalthoffm, H., and Stöckle, M. (1998). Differential mucin MUC7 gene expression in invasive bladder carcinoma in contrast to uniform MUC1 and MUC2 gene expression in both normal urothelium and bladder carcinoma. Cancer Res. 58, 5662-5666.

St Hill, C. A. (2011). Interactions between endothelial selectins and cancer cells regulate metastasis. Front. Biosci. 16, 3233-3251.

Tewes, M., Aktas, B., Welt, A., Mueller, S. Hauch, S., Kimmig, R., and KasimirBauer, S. (2009). Molecular profiling and predictive value of circulating tumor cells in patients with metastatic breast cancer: an option for monitoring response to breast cancer related therapies. Breast Cancer Res. Treat. 115, 581-590.

Tremblay, P. L., Huot, J., and Auger, F. A. (2008). Mechanisms by which Eselectin regulates diapedesis of colon cancer cells under flow conditions. Cancer Res. 68, 5167-5176.

Varki, N. M., and Varki, A. (2007). Diversity in cell surface sialic acid presentations: implications for biology and disease. Lab. Invest. 87, 851-857.
Wirtz, D., Konstantopoulos, K., and Searson, P. C. (2011). The physics of cancer: the role of physical interactions and mechanical forces in metastasis. Nat. Rev. Cancer 11, 512-522.

Zen, K., Liu, D.-Q., Guo, Y.-L., Wang, C., Shan, J., Fang, M., Zhang, C. Y., and Liu, Y. (2008). CD44v4 is a major E-selectin ligand that mediates breast cancer cell transendothelial migration. PLoS ONE 3, e1826 doi:10.1371/journal.pone.0001826

Zotter, S., Lossnitzer, A., Hageman, P. C., Delemarre, J. F. M., Hilkens, J., and Hilgers, J. (1987). Immunohistochemical localization of the epithelial marker mam6 in invasive malignancies and highly dysplastic adenomas of the large-intestine. Lab. Invest. 57, 193-199.

Conflict of Interest Statement: The authors declare that the research was conducted in the absence of any commercial or financial relationships that could be construed as a potential conflict of interest.

Received: 18 May 2012; accepted: 03 July 2012; published online: 27 July 2012.

Citation: Geng Y, Yeh K, Takatani T and King MR (2012) Three to tango: MUC1 as a ligand for both E-selectin and ICAM-1 in the breast cancer metastatic cascade. Front. Oncol. 2:76. doi: 10.3389/fonc. 2012.00076

This article was submitted to Frontiers in Cancer Molecular Targets and Therapeutics, a specialty of Frontiers in Oncology. Copyright (c) 2012 Geng, Yeh, Takatani and King. This is an open-access article distributed under the terms of the Creative Commons Attribution License, which permits use, distribution and reproduction in other forums, provided the original authors and source are credited and subject to any copyright notices concerning any third-party graphics etc. 